\title{
A comprehensive analysis of adiponectin QTLs using SNP association, SNP cis-effects on peripheral blood gene expression and gene expression correlation identified novel metabolic syndrome (MetS) genes with potential role in carcinogenesis and systemic inflammation
}

Yi Zhang ${ }^{1,2^{*}}$, Jack W Kent Jr ${ }^{3}$, Michael Olivier ${ }^{4}$, Omar Ali ${ }^{5}$, Diana Cerjak ${ }^{1,2}$, Ulrich Broeckel ${ }^{2,5}$, Reham M Abdou ${ }^{1,2}$, Thomas D Dyer ${ }^{3}$, Anthony Comuzzie ${ }^{3}$, Joanne E Curran ${ }^{3}$, Melanie A Carless ${ }^{3}$, David L Rainwater ${ }^{3}$, Harald H H Göring ${ }^{3}$, John Blangero ${ }^{3}$ and Ahmed H Kissebah ${ }^{1,2}$

\footnotetext{
Abstract

Background: Metabolic syndrome (MetS) is an aberration associated with increased risk for cancer and inflammation. Adiponectin, an adipocyte-produced abundant protein hormone, has countering effect on the diabetogenic and atherogenic components of MetS. Plasma levels of adiponectin are negatively correlated with onset of cancer and cancer patient mortality. We previously performed microsatellite linkage analyses using adiponectin as a surrogate marker and revealed two QTLs on chr5 (5p14) and chr14 (14q13).

Methods: Using individuals from 85 extended families that contributed to the linkage and who were measured for 42 clinical and biologic MetS phenotypes, we tested QTL-based SNP associations, peripheral white blood cell (PWBC) gene expression, and the effects of cis-acting SNPs on gene expression to discover genomic elements that could affect the pathophysiology and complications of MetS.

(Continued on next page)
}

\footnotetext{
* Correspondence: yzhang@mcw.edu

${ }^{1}$ TOPS Obesity and Metabolic Research Center, Department of Medicine,

Medical College of Wisconsin, Milwaukee, Wisconsin, USA

${ }^{2}$ Human and Molecular Genetics Center, Medical College of Wisconsin,

Milwaukee, Wisconsin, USA

Full list of author information is available at the end of the article
} 
(Continued from previous page)

Results: Adiponectin levels were found to be highly intercorrelated phenotypically with the majority of MetS traits. QTL-specific haplotype-tagging SNPs associated with MetS phenotypes were annotated to 14 genes whose function could influence MetS biology as well as oncogenesis or inflammation. These were mechanistically categorized into four groups: cell-cell adhesion and mobility, signal transduction, transcription and protein sorting. Four genes were highly prioritized: cadherin 18 (CDH18), myosin X (MYO10), anchor protein 6 of AMPK (AKAP6), and neuronal PAS domain protein 3 (NPAS3). PWBC expression was detectable only for the following genes with multi-organ or with multi-function properties: NPAS3, MARCH6, MYO10 and FBXL7. Strong evidence of cis-effects on the expression of MYO10 in PWBC was found with SNPs clustered near the gene's transcription start site. MYO10 expression in PWBC was marginally correlated with body composition $(p=0.065)$ and adipokine levels in the periphery $(p=0.064)$. Variants of genes AKAP6, NPAS3, MARCH6 and FBXL7 have been previously reported to be associated with insulin resistance, inflammatory markers or adiposity studies using genome-wide approaches whereas associations of $\mathrm{CDH} 18$ and MYO10 with MetS traits have not been reported before.

Conclusions: Adiponectin QTLs-based SNP association and mRNA expression identified genes that could mediate the association between MetS and cancer or inflammation.

Keywords: Adiponectin, Metabolic syndrome, Cancer risk, Inflammation

\section{Background}

MetS is a cluster of phenotypes characterized by preferential deposition of fat in the abdominal/visceral region, insulin resistance, dyslipidemia, increased blood pressure and increased plasma levels of adipokines/ cytokines [1]. Its complications include increased blood pressure/hypertension, glucose intolerance and type 2 diabetes. MetS has been associated with several forms of cancer including breast, endometrial, cervical, ovarian, esophageal, colon, rectal, pancreatic, hepatic, biliary and kidney cancers [2]. Overweight/obesity by itself accounts for $14 \%$ of cancer deaths in men and $20 \%$ in women [2]. Childhood cancer survivors are also known to present features of the MetS in later life [3].

Adiponectin is an adipocyte-produced kinin encoded by the gene apM1 (adipose most abundant transcript 1) at chr3q27 [4]. Adiponectin circulates in two forms, the low molecular weight (LMW) dimers, and the high molecular weight (HMW) oligomers. Tissue specificity of adiponectin $n$-mers is determined by their relative affinity for receptors (AdipoR1 and R2). AdipoR1 has a higher affinity for HMW. It is ubiquitously expressed but highly enriched in skeletal muscle. AdipoR2 can bind both forms and is mainly expressed in the liver [5]. Adiponectin has been shown to enhance insulin sensitivity and to exert anti-diabetogenic and anti-atherogenic functions as well as anti-inflammatory and anti-angiogenic activities [6-8]. Its plasma levels are inversely correlated with increased risk for obesity-related malignancies [9].

To explore possible genetic mechanisms linking MetS pathways with severe adverse outcomes such as development of cancer, we previously conducted a genome-wide linkage study using microsatellite markers at approximately 10 centiMorgan (cM) intervals in 1,100 individuals from 170 nuclear families (out of 85 extended families) of predominantly Northern European ancestry. This study identified two highly significant quantitative trait loci (QTLs) on chr5p14 and chr14q13 [10]. In the present study, we tested for genes harbored within these QTLs that could account for the association between MetS and carcinogenesis or systemic inflammation. For this purpose, we evaluated 1,137 individuals from the 85 extended families that contributed to the original linkage signals and who were phenotyped for 42 clinical and/or biological MetS traits (described in Results). We then performed QTL-focused SNP association and PWBC target gene expression analyses to identify those genes predisposing for this association.

\section{Methods}

\section{Subjects and phenotypes}

The present study cohort included 1,137 individuals from 85 extended families. Details of their recruitment and ascertainment traits procedures have been previously described $[11,12]$. Recruitment was initiated via an obese proband $(\mathrm{BMI} \geq 30$ ) with minimal availability of one obese and one never-obese (BMI $\leq 27)$ siblings and at least one, preferably both, parents. The clinical phenotypic components, which included weight, height, BMI, waist circumference (WC), hip circumference (HC), waist to hip ratio (WHR), fasting glucose (FG), fasting insulin (FI), insulin to glucose ratio (IGR), homeostasis model assessment (HOMA), plasma triglycerides (TG), total cholesterol (TC), LDL-cholesterol (LDL-c) and calculated LDL-cholesterol levels (cal. LDL-c), HDLcholesterol (HDL-c), systolic and diastolic blood pressure (sBP and $\mathrm{dBP}$ ) and pulse, as described [11]. The biological traits included total fat mass both in kilogram and percentage (Fatkg and Fatpct) and total fat free mass both in kilograms and as percentage of total body mass (Leankg and 
Leanpct) by DXA (Dual-emission X-ray absorptiometry) [13]; total abdominal, visceral and subcutaneous fat size (TAF, VF and SubQF) by computed tomography (CT) scans of the fourth lumbar spine [14]; respiratory quotient (RQ) and resting energy expenditure (REE) measured in resting subjects using a Deltatrac Indirect Calorimeter (Sensor Medics, VIASYS Healthcare, Conshohocken, PA) after a $10 \mathrm{hr}$ fast; insulin/glucose responsiveness indices: insulin sensitivity (SI), glucose effectiveness (SG), acute insulin response to glucose $\left(\mathrm{AIR}_{\mathrm{G}}\right)$ and disposition index (DI) by Minimal Model [15]; lipids/lipoprotein sizing [HDL median diameter (HMED), LDL-cholesterol median diameter (LMEDn), LDL-cholesterol dominant peak diameter (LDLppd) and apoB-containing non-HDL median diameter (BMED) which includes VLDL, ILDL, LP $\alpha$ and LDL] measured by polyacrylamide gradient gel electrophoresis [16]; circulating levels of adiponectin, leptin by a double antibody, equilibrium RIA (Millipore Corporation, Billerica, MA); and TNF-alpha, interleukin-1beta (IL-1 $\beta$ ) and interleukin-6 (IL-6)] measured as described [17]. All study procedures for adults and children were approved by the Institutional Review Boards of the Medical College of Wisconsin and Children's Hospital of Wisconsin, respectively. Informed consent was obtained from the participating subjects or guardians of participating minors.

\section{SNP genotyping and data cleaning}

Genomic DNA was extracted and prepared from whole blood using commercial kits (Puregene, Minneapolis, MN). Genome-wide SNP genotyping was performed using Affymetrix Genome-Wide Human SNP 6.0 arrays and SNP calls were generated by Genotype Console 3.2. Individuals with fewer than $95 \%$ of all available markers called were excluded. 869,222 autosomal SNPs were prepared by Preswalk and checked for Mendelian consistency with SimWalk2. A SNP was eliminated if: 1) fewer than 95\% of the cohort were typed successfully; 2) the SNP was monoallelic; 3) the SNP had more than two alleles; 4) fewer than five copies of the SNP existed in the current study cohort. Hardy-Weinberg equilibrium (HWE) was tested for each SNP using SOLAR [18]; SNPs with excessive deviation from HWE $\left(\mathrm{p}<10^{-8}\right)$ were excluded. Missing SNP data were imputed with MERLIN [19].

\section{Transcriptional profiling}

Genome-wide transcriptional profiles of a subset of the SNP genotyping cohort (369 individuals from 55 nuclear families) were obtained as previously described [20] with modifications. Briefly, for each individual $2.5 \mathrm{ml}$ blood was collected into a PAXgene ${ }^{\circ}$ Blood RNA Tube (BD, Franklin Lakes, NJ) following an overnight fast. Total RNA was isolated from each tube using the PAXgene Blood RNA Kit (Qiagen, Valencia, CA) and anti-sense RNA (aRNA) was synthesized using the MessageAmp II-Biotin aRNA kit
(Ambion, Austin, TX). A total of $1.5 \mu \mathrm{g}$ aRNA was hybridized to Illumina HumanWG-6 version 2 or version 3 chips (Illumina, San Diego, CA) and expression detected on the Illumina ${ }^{\circledR}$ BeadArray ${ }^{\text {TM }}$ 500GX Reader. Illumina GenomeStudio software (version 2010.3) was used for preliminary data analysis with standard background normalization. The data discussed in this publication have been deposited in NCBI's Gene Expression Omnibus [21] and are accessible through GEO Series accession number GSE45987 (http://www.ncbi.nlm.nih.gov/geo/query/acc.cgi? acc $=$ GSE45987).

\section{Statistical analysis \\ Measured genotype analysis}

In SOLAR, each SNP genotype was converted to a covariate measure equal to 0,1 or 2 copies of the minor allele (or, for missing genotypes, a weighted covariate based on imputation). These covariates were included in variance-components mixed models for measured genotype analyses [22] versus null models that incorporated the random effect of kinship and fixed effects such as age, age ${ }^{2}$, sex and their interactions. Individual scores from a principal components analysis of representative SNPs were also included to correct for possible population stratification [23].

Within chromosomal regions showing the strongest prior evidence of linkage (as logarithm of odds, LOD, score) with MetS traits in our MRC-OB cohort, we selected all available SNPs on the Affymetrics 6.0 array that mapped within a 1-LOD confidence interval of the maximum LOD score in each region. Each SNP covariate was tested independently in a 1 degree of freedom likelihood ratio test. To take into account the linkage disequilibrium between SNPs in each region, we calculated the effective number of independent SNPs $\left(\mathrm{N}_{\text {eff }}\right)$ using the method of Moskvina \& Schmidt [24]. Critical p-values were calculated using Bonferroni/Šidák correction for each linkage region based on its $\mathrm{N}_{\text {eff }}$.

\section{Gene expression analysis}

Microarray data were available in two batches, one based on Version 2 arrays (48,701 probes, 307 samples) and the other on Version 3 (48,803 probes, 230 samples). To guard against possible batch effects and probe differences, each batch was analyzed separately: The number of probe transcripts detectable at $\mathrm{p} \leq 0.05$ by BeadStudio software was counted, a false discovery rate (FDR) was computed across all probes, and transcripts detectable at $5 \%$ FDR were retained. Expression levels were $\log _{2}$ transformed and inverse-quartile normalized. Transformed and normalized expression levels for probes that mapped to the 1-LOD QTL regions were tested for association with phenotypes of interest in models that included the random effect of kinship. Gene-centric p-values were calculated by 
combining independent $\mathrm{p}$-values from the two microarray batches and multiple probes using Stouffer's weighted Z-score method [25] implemented in R.

\section{Results}

\section{Intercorrelation between plasma adiponectin levels and} MetS phenotypes

Based on their attributes in different biological pathways, we categorized our 42 measured MetS phenotypes into five groups: body composition, insulin responsiveness, lipids/lipoprotein profiles, cardiovascular performance, and adipokine and cytokines (Table 1). Means \pm SD of the 42 MetS phenotypes and levels of their heritability have been previously described [26]. We found that plasma adioponectin levels were highly heritable (additive heritability, $\mathrm{h}^{2}=0.48$ ) in our study cohort. Intercorrelation analysis of leading MetS component phenotypes revealed significant phenotypic correlations to varied degrees (See the Additional file 1: Table S1). Plasma adiponectin is also significantly correlated with the majority of tested phenotypes (29 out of 41, nominal $\mathrm{p}<0.05)$. In particular, it is highly correlated with the MetS-defining [27,28] phenotypes WC (correlation $\mathrm{p}$-value $\left.=1.86 \times 10^{-22}\right)$, FG $\left(7.8 \times 10^{-4}\right)$, plasma TG $\left(1.3 \times 10^{-8}\right)$, plasma HDL-c $\left(5.2 \times 10^{-12}\right)$, sBP $\left(1.55 \times 10^{-6}\right)$ and $\mathrm{dBP}$ $\left(7.1 \times 10^{-3}\right)$. Overall, levels of adiponectin inversely correlate with a phenotypes representing adverse adipose distribution (weight, BMI, WC, HC, WHR, Fatkg, Fatpct and SubQF, VF and TAF), elevated fasting glucose levels and insulin resistance indices (FG, FI, IGR and HOMA), dyslipidemia (TG), cardiovascular malfunction (sBP, dBP and pulse) and leptin. On the contrary, adiponectin levels correlate positively with several phenotypes indexing leanness (Leanpct), insulin sensitivity (SI and SG) and HDL-c. These results indicate that adiponectin is a reliable and significant phenotypic surrogate of both the clinical and biological traits of MetS in our cohort.

\section{SNP genotype/phenotype association}

Consistent with common practice, we defined confidence regions for the previously defined adiponectin linkage peaks as the physical positions adjacent to the peak showing linkage evidence of at least LOD score - 1: 5p14 [peak LOD=4.1; chr5: 9,792,000-23,021,100bp (NCBI36/ hg18)] and 14q13 [peak LOD=3.2; chr14: 23,131,00036,761,868bp (NCBI36/hg18)]. Haplotype-tagging SNPs located within these regions were tested for statistical association with each of the $42 \mathrm{MetS}$ phenotypes. To account for multiple testing within QTLs while accounting for linkage disequilibrium (LD) among SNPs, QTLspecific significance thresholds were calculated based upon Bonferroni/Šidák correction for the effective number of independent SNPs at $5 \mathrm{p} 14\left(\mathrm{n}_{\mathrm{SNPs}}=3540, \mathrm{n}_{\text {effective }}=\right.$ 2429.61, $\left.\mathrm{p}_{\alpha=0.05}=2.11 \times 10^{-5}\right)$ and $14 \mathrm{q} 13 \quad\left(\mathrm{n}_{\mathrm{SNPs}}=3794\right.$, $\left.\mathrm{n}_{\text {effective }}=2760.37, \mathrm{p}_{\alpha=0.05}=1.86 \times 10^{-5}\right)$. SNPs that passed region-specific significance thresholds for respective traits and/or the highest nominally significant SNP of each trait for each trait are shown in Tables 2 and 3.

\section{QTL5p14}

Fine-mapping of this region identified QTL-wide significant SNP associations with body composition phenotypes, including weight and BMI (Figure 1A and 1B). As shown in Table 2, 7 SNPs led by rs10061119 are mapped to an intronic region of the gene encoding cadherin 18 (CDH18). In addition, SNPs annotated near myosin X (MYO10), showed nominally significant associations with plasma adiponectin (Table 2 and Figure 1C). The second strongest SNP association cluster with adiponectin (Figure 1C, pointed by a red arrow) is intergenic and is approximately $400 \mathrm{~kb} 5$ to the transcription start site of the cadherin-18 gene $\mathrm{CDH} 18$ (Figure $1 \mathrm{C}$, framed in green).

SNPs mapped to CDH18 (cadherin 18) were also nominally associated with other MetS phenotypes including WC, HC and RQ. SNP rs404639 mapped to an intron of $C D H 12$, another member of the cadherin family, and was associated with plasma leptin. SNP rs6894869 was significantly associated with lipid particle size phenotype BMED and mapped to an intron of CTNND2, which functions in the same pathway as cadherins, plays a crucial role in CNS development [29] and is a partner of the Alzheimer disease-associated gene presenilin-1 [30]. MYO10 was also nominally associated with Leankg, LDLppd and IL-6. For the other MetS traits the strongest associations were with SNPs near several other genes with biological relevance to cancer. SNPs near TAG, a tumor antigen gene, were associated with HMED (high density lipid particle sizing), REE (resting energy expenditure), and insulin phenotypes FG and HOMA. SNPs mapped to MARCH11 and FBXL7, two ubiquitin ligases involved in the pro-inflammation pathways, were associated with total fat mass, FI, SI and pro-inflammation marker IL-1beta (MARCH11), and with lean body mass (FBXL7).

\section{QTL14q13}

This QTL region has a high density of genes with regulatory functions including signal transduction, transcription and post-transcription processing. Our fine-mapping identified SNPs associated with each of the 42 MetS phenotypes. Table 3 summarizes the SNPs most highly associated with each trait, the attributes of the variants, and the gene ontology of their annotated genes. Variants of NPAS3, a neuronal transcription factor thought to be involved in brain tumor suppression, were found to be associated with 11 of the MetS phenotypes (Fatkg, Leankg, SubQF, TAF, REE, TG, TC, LDL-c, pulse, IL1b and IL-6), suggesting a 
Table 1 Correlations of plasma adiponectin with the other MetS phenotypes in our cohort

\begin{tabular}{|c|c|c|c|}
\hline & Phenotype & Correlation $\mathrm{p}$-value & Inter-correlation ( $\rho)$ \\
\hline \multirow[t]{17}{*}{ Body composition } & Weight, kg & $7.37 \times 10^{-17}$ & -0.29 \\
\hline & Height, cm & 0.030 & -0.08 \\
\hline & $\mathrm{BMl}, \mathrm{kg} / \mathrm{m}_{2}$ & $4.22 \times 10^{-16}$ & -0.29 \\
\hline & Waist circumference (WC), $\mathrm{cm}$ & $1.90 \times 10^{-22}$ & -0.34 \\
\hline & Hip circumference $(\mathrm{HC}), \mathrm{cm}$ & $4.80 \times 10^{-16}$ & -0.29 \\
\hline & Waist to Hip ratio (WHR) & 0.000025 & -0.15 \\
\hline & Total Fat Mass (Fatkg), kg & 0.00078 & -0.17 \\
\hline & Total Fat Mass (Fatpct),\% & 0.032 & -0.11 \\
\hline & Total Lean Mass (Leankg), kg & 0.00013 & -0.20 \\
\hline & Total Lean Mass (Leanpct), \% & 0.026 & 0.11 \\
\hline & Subcutaneous Fat (SubQF), g & 0.0012 & -0.18 \\
\hline & Visceral Fat (VF), g & $2.04 \times 10^{-8}$ & -0.30 \\
\hline & Total Abdominal Fat (TAF), g & 0.000039 & -0.23 \\
\hline & Respiratory Quotient (RQ) & 0.78 & 0.02 \\
\hline & Resting Energy Expenditure (REE), kcal/24 hrs & $8.15 \times 10^{-7}$ & -0.26 \\
\hline & REE/weight, kcal/24hrs/kg & 0.29 & 0.06 \\
\hline & REE/Lean mass (REE/LM), kcal/24hrs/kg & 0.16 & -0.08 \\
\hline \multirow[t]{8}{*}{ Insulin responsiveness } & Fasting Glucose (FG), mmol/l & 0.00078 & -0.12 \\
\hline & Fasting Insulin (Fl),pmol// & $8.85 \times 10-8$ & -0.18 \\
\hline & Insulin/glucose (IGR) & $6.63 \times 10^{-6}$ & -0.15 \\
\hline & Homeostasis model assessment (HOMA) & $3.40 \times 10^{-8}$ & -0.19 \\
\hline & Insulin Sensitivity $(\mathrm{SI}),\left(\times 10^{-4} / \mathrm{min} / \mu \mathrm{U} / \mathrm{ml}\right)$ & $1.28 \times 10^{-6}$ & 0.26 \\
\hline & Glucose Effectiveness (SG), $\mathrm{min}^{-1}$ & 0.068 & 0.10 \\
\hline & Acute Insulin Response to glucose $\left(A \mid R_{G}\right), \mu \mathrm{U} / \mathrm{ml} \times 10 \mathrm{~min}$ & 0.45 & -0.04 \\
\hline & Disposition Index (DI), AUC (Insulin $\left.{ }_{0-10 ~ m i n}\right) \times S I$ & 0.012 & 0.14 \\
\hline \multirow[t]{9}{*}{ Lipids/lipoprotein profiles } & Triglycerides $(\mathrm{TG}), \mathrm{mmol} / \mathrm{l}$ & $1.30 \times 10^{-8}$ & -0.20 \\
\hline & Total Cholesterol (TC), mmol/l & 0.50 & -0.02 \\
\hline & LDL-cholesterol (LDL-c), mmol/l & 0.42 & -0.03 \\
\hline & Calculated LDL-C (cal. LDL-c), mmol/l & 0.92 & 0.00 \\
\hline & HDL-cholesterol (HDL-c), mmol/l & $5.17 \times 10^{-12}$ & 0.25 \\
\hline & HMED, nm & 0.000020 & 0.18 \\
\hline & LMEDn, nm & 0.000851 & 0.14 \\
\hline & LDLppd, nm & $4.43 \times 10^{-6}$ & 0.19 \\
\hline & BMED, nm & 0.058 & 0.08 \\
\hline \multirow[t]{3}{*}{ Cardiovascular performance } & Systolic Blood Pressure (sBP), mmHg & $1.55 \times 10^{-6}$ & -0.16 \\
\hline & Diastolic Blood Pressure (dBP), mmHg & 0.0071 & -0.09 \\
\hline & Pulse, beats/min & 0.023 & -0.08 \\
\hline \multirow[t]{4}{*}{ Adipokine and cytokines } & Leptin, $\mathrm{ng} / \mathrm{ml}$ & $5.64 \times 10^{-11}$ & -0.23 \\
\hline & TNF-alpha, pg/ml & 0.24 & 0.04 \\
\hline & Interleukin-1 beta $(\mathrm{IL}-1 \beta), \mathrm{pg} / \mathrm{ml}$ & 0.89 & 0.01 \\
\hline & Interleukin-6 (IL-6), pg/ml & 0.81 & -0.01 \\
\hline
\end{tabular}

The pair-wise intercorrelation $(\rho)$ and its respective significance ( $p$-value) between plasma adiponectin levels and each of the other MetS phenotypes are shown. Inter-correlations that passed the nominal significance cutoff $(p<0.05)$ are depicted in bold italic. 
Table 2 MetS SNP association with phenotypes and their gene annotation at 5p14 QTL

\begin{tabular}{|c|c|c|c|c|c|c|c|}
\hline Variant & Minor allele & MAF & -LOG(p) & Associated phenotypes & Nearest gene & Location & Annotation \\
\hline rs10061119 & $T$ & 0.26 & 5.07 & Weight & $\mathrm{CDH} 18$ & intron & Cell Cell adhesion \\
\hline rs13357704 & A & 0.26 & 5.07 & Weight & $\mathrm{CDH} 18$ & intron & Cell Cell adhesion \\
\hline rs10805723 & G & 0.25 & 5.03 & Weight & $\mathrm{CDH} 18$ & intron & Cell Cell adhesion \\
\hline rs16887308 & T & 0.26 & 5.03 & Weight & $\mathrm{CDH} 18$ & intron & Cell Cell adhesion \\
\hline rs4386736 & A & 0.26 & 5.03 & Weight & $\mathrm{CDH} 18$ & intron & Cell Cell adhesion \\
\hline rs6879762 & C & 0.26 & 5.03 & Weight & $\mathrm{CDH} 18$ & intron & Cell Cell adhesion \\
\hline rs10062513 & G & 0.25 & 4.68 & Weight & $\mathrm{CDH} 18$ & intron & Cell Cell adhesion \\
\hline rs13355121 & C & 0.25 & 4.68 & Weight & $\mathrm{CDH} 18$ & intron & Cell Cell adhesion \\
\hline rs10062864 & A & 0.25 & 4.57 & Weight & $\mathrm{CDH} 18$ & intron & Cell Cell adhesion \\
\hline rs163282 & A & 0.26 & 4.27 & Height & FAM134B & intron & Neuron maintenance \\
\hline rs10061119 & T & 0.26 & 4.82 & BMI & $\mathrm{CDH} 18$ & intron & Cell Cell adhesion \\
\hline rs13357704 & A & 0.26 & 4.82 & BMl & $\mathrm{CDH} 18$ & intron & Cell Cell adhesion \\
\hline rs10805723 & G & 0.25 & 4.77 & BMI & $\mathrm{CDH} 18$ & intron & Cell Cell adhesion \\
\hline rs16887308 & T & 0.26 & 4.77 & BMl & $\mathrm{CDH} 18$ & intron & Cell Cell adhesion \\
\hline rs4386736 & A & 0.26 & 4.77 & BMI & $\mathrm{CDH} 18$ & intron & Cell Cell adhesion \\
\hline rs6879762 & C & 0.26 & 4.77 & BMl & $\mathrm{CDH} 18$ & intron & Cell Cell adhesion \\
\hline rs13355121 & C & 0.25 & 4.52 & BMI & $\mathrm{CDH} 18$ & intron & Cell Cell adhesion \\
\hline rs10062864 & A & 0.25 & 4.43 & BMI & $\mathrm{CDH} 18$ & intron & Cell Cell adhesion \\
\hline rs10061119 & T & 0.26 & 4.66 & WC & $\mathrm{CDH} 18$ & intron & Cell Cell adhesion \\
\hline rs13357704 & A & 0.26 & 4.66 & WC & $\mathrm{CDH} 18$ & intron & Cell Cell adhesion \\
\hline rs10805723 & G & 0.25 & 4.57 & WC & $\mathrm{CDH} 18$ & intron & Cell Cell adhesion \\
\hline rs16887308 & T & 0.26 & 4.57 & WC & $\mathrm{CDH} 18$ & intron & Cell Cell adhesion \\
\hline rs4386736 & A & 0.26 & 4.57 & WC & $\mathrm{CDH} 18$ & intron & Cell Cell adhesion \\
\hline rs6879762 & C & 0.26 & 4.57 & WC & $\mathrm{CDH} 18$ & intron & Cell Cell adhesion \\
\hline rs995021 & C & 0.49 & 3.57 & $\mathrm{HC}$ & $\mathrm{CDH} 18$ & intron & Cell Cell adhesion \\
\hline rs1864220 & G & 0.07 & 3.45 & WHR & FBXL7 & intron & Protein sorting \\
\hline rs 860545 & T & 0.16 & 2.89 & Fatkg & MARCH11 & intergenic & Protein sorting \\
\hline rs10223312 & T & 0.01 & 3.52 & Fatpct & mRNA BC033144 & intergenic & unknown function \\
\hline rs17707882 & A & 0.04 & 4.47 & Leankg & MYO10 & intron & Cell Cell adhesion \\
\hline rs10223312 & T & 0.01 & 3.54 & Leanpct & mRNA BC033144 & intergenic & unknown function \\
\hline rs1840870 & C & 0.44 & 2.44 & SubQF & EST BG220738 & intergenic & unknown function \\
\hline rs11134371 & $\mathrm{T}$ & 0.33 & 4.04 & VF & LOC285692 & intron & unknown function \\
\hline rs17275322 & G & 0.03 & 2.82 & TAF & LOC285692 & intron & unknown function \\
\hline rs12652510 & C & 0.19 & 3.11 & $\mathrm{RQ}$ & $\mathrm{CDH} 18$ & intron & Cell Cell adhesion \\
\hline rs10065719 & G & 0.14 & 2.74 & REE & AY330599 & intergenic & tumor antigen \\
\hline rs6859862 & C & 0.41 & 3.61 & REE/weight & DNAH5 & intron & motor protein \\
\hline rs1809880 & G & 0.06 & 3.16 & REE/Lean & ROPNIL & intron & sperm protein \\
\hline rs7721328 & G & 0.17 & 3.57 & FG & mRNA TAG1 & intron & tumor antigen \\
\hline rs2582660 & C & 0.18 & 2.88 & $\mathrm{FI}$ & MARCH11 & intergenic & Protein sorting \\
\hline rs16902967 & A & 0.03 & 3.77 & IGR & DNAH5 & intergenic & motor protein \\
\hline rs4327597 & A & 0.14 & 3.25 & HOMA & TAG & intron & tumor antigen \\
\hline rs831657 & G & 0.14 & 3.23 & $\mathrm{SI}$ & MARCH11 & intergenic & protein sorting \\
\hline rs1551936 & T & 0.15 & 3.44 & SG & FAM134B & intron & Neuron maintenance \\
\hline rs2929724 & C & 0.50 & 3.30 & AIR & LOC285696 & intron & unknown function \\
\hline
\end{tabular}


Table 2 MetS SNP association with phenotypes and their gene annotation at 5p14 QTL (Continued)

\begin{tabular}{|c|c|c|c|c|c|c|c|}
\hline rs10805650 & G & 0.33 & 3.11 & DI & EST BM682321 & intergenic & unknown function \\
\hline rs16887451 & $C$ & 0.07 & 3.10 & TG & mRNA BC028204 & intron & unknown function \\
\hline rs17839277 & $\mathrm{T}$ & 0.03 & 3.55 & TC & mRNA BC028204 & intergenic & unknown function \\
\hline rs12659663 & A & 0.25 & 4.17 & LDL-C & mRNA BC028204 & intron & unknown function \\
\hline rs12659663 & A & 0.25 & 3.87 & cal. LDL-c & mRNA BC028204 & intron & unknown function \\
\hline rs6883134 & G & 0.06 & 3.25 & $\mathrm{HDL}-\mathrm{C}$ & TRIO mRNA & intron & protein interaction \\
\hline rs10065719 & G & 0.14 & 4.48 & HMED & AY330599 & intergenic & tumor antigen \\
\hline rs10079252 & G & 0.49 & 4.30 & LMEDn & mRNA U92022 & intergenic & transposon Hsmar2 \\
\hline rs10073730 & $C$ & 0.01 & 3.77 & LDLppd & MYO10 & intron & Cell Cell adhesion \\
\hline rs6894869 & $C$ & 0.01 & 5.13 & BMED & CTNND2 & intron & Cell Cell adhesion \\
\hline rs5745297 & $A$ & 0.07 & 3.58 & sBP & $D A P$ & $3^{\prime}$ UTR & cell death \\
\hline rs6450583 & G & 0.21 & 3.27 & $d B P$ & mRNA BC028204 & intergenic & unknown function \\
\hline rs1971391 & A & 0.44 & 3.10 & Pulse & mRNA AK130861 & intergenic & unknown function \\
\hline rs31509 & G & 0.28 & 3.33 & Adiponectin & MYO10 & intron & Cell Cell adhesion \\
\hline rs404639 & G & 0.06 & 4.29 & Leptin & $\mathrm{CDH} 12$ & intron & Cell Cell adhesion \\
\hline rs6893920 & G & 0.22 & 4.04 & TNF-alpha & mRNA U92022 & intergenic & transposon Hsmar2 \\
\hline rs7730897 & $\mathrm{T}$ & 0.10 & 3.47 & $I L-1 \beta$ & MARCH11 & intergenic & protein sorting \\
\hline rs17707882 & A & 0.04 & 3.77 & IL-6 & MYO10 & intron & Cell Cell adhesion \\
\hline
\end{tabular}

SNPs within 1 LOD reduction from the linkage peak were tested for associations against the 42 phenotypes. Annotated genes and their known function were derived from the NCBI build 36 human genome assembly. Annotations were determined at the position and within $250 \mathrm{~kb}$ up- and downstream of the associated SNP. Data shown in column "-Log10(p)" are levels of the highest association. SNP associations that exceed statistical QTL-specific significance threshold are bolded.

pleitropic effect (Table 3). Two of these associations (TG and TC) were borderline significant, marginally reaching the regional threshold (Table 3 and Figure $2 \mathrm{~A}$ ). SNPs near BRMS1L, a breast cancer suppressor gene, was associated with LMEDn and LDLppd. SNPs of $E G L N 3$, a regulator of transcription factor HIF that affects apoptosis in hemangioblastoma and clear cell renal cancer, were associated with IGR and LDL-c. SNPs of NOVA1, a post-transcription processing of the GnRH paraneoplastic antigen, were associated at nominal significance with several phenotypes including weight, BMI, WC, FG, FI, HOMA, SI, AIR, and sBP.

Prominent SNP associations in this region were mapped to genes for signal transducers include kinases and kinase-related proteins AKAP6 and PRKD1 and the phosphotase PPP2R3C. SNPs of the gene encoding AKAP6, an anchor protein for AMPK, which may connect MetS with cancer, were associated with $\mathrm{HC}, \mathrm{RQ}$ and REE/leanmass. SNPs of PRKD1, a kinase that phosphorylates and therefore activates E-cadherin functions, were associated with WHR, Fatpct, Leanpct, and TNF-alpha. SNPs of PPP2R3C, a protein phosphatase, were associated with DI. SNP rs9322942 of SRP54, the gene for a signal recognition particle protein, is associated with adiponectin. Figure 2 shows the SNP association patterns with phenotypes RQ and TG at this QTL.

\section{The cis-SNP effects on gene expression}

To test the function of the interrogated SNPs of the two adiponectin QTLs, we evaluated the effect of each variant on the levels of transcripts produced from the genes located within these two regions. We surveyed transcripts that were robustly detectable after filtering through our quality control procedures (see Methods). We then assessed the association between QTL-specific SNPs and each transcript annotated to the same locus.

Figure 3 shows the effects of SNPs of the chr5 locus on expression of MYO10. We found strong signals clustering in proximity to the transcription start site (TSS) of MYO10. SNPs exhibiting the strongest cis-effects (lowest $\mathrm{p}$-value $=5.43 \times 10^{-6}$ ) are in high linkage disequilibrium (data not shown) and span a $17 \mathrm{~kb}$ region that has been shown previously to be highly important for transcription initiation [31-34].

We further analyzed the relationship between $M Y O 10$ gene expression patterns in PWBC and key MetS phenotypes for which we had found evidence of SNP-phenotype associations (Table 2). Table 4 shows the levels of the correlations between the level of $M Y O 10$ gene expression and MetS traits. We found positive correlations of MYO10 expression with measures of adiposity. MYO10 expression correlated negatively with plasma levels of adiponectin (although this did not reach statistical significance) and was positively correlated with plasma leptin at 
Table 3 MetS SNP association with phenotypes and their gene annotation at 14q13 QTL

\begin{tabular}{|c|c|c|c|c|c|c|c|}
\hline Variant & $\begin{array}{c}\text { Minor } \\
\text { allele }\end{array}$ & MAF & $-\operatorname{LOG}(p)$ & $\begin{array}{l}\text { Associated } \\
\text { phenotypes }\end{array}$ & Nearest gene & Location & Annotation \\
\hline rs1955850 & G & 0.33 & 2.95 & Weight & NOVA1 & intergenic & post-transcription regulation \\
\hline rs2332524 & G & 0.10 & 2.87 & Height & STXBPG & intergenic & exocytosis \\
\hline rs1955850 & G & 0.33 & 3.75 & BMl & NOVA1 & intergenic & post-transcription regulation \\
\hline rs6574794 & A & 0.06 & 3.08 & WC & NOVA1 & intergenic & post-transcription regulation \\
\hline rs1956993 & C & 0.09 & 2.92 & $\mathrm{HC}$ & AKAP6 & intergenic & signal transduction \\
\hline rs17096124 & G & 0.03 & 3.81 & WHR & PRKD1 & intron & signal transduction \\
\hline rs8007613 & G & 0.28 & 2.88 & Fatkg & NPAS3 & intron & Transcription regulation \\
\hline rs41449149 & $\mathrm{T}$ & 0.07 & 3.45 & Fatpct & PRKD1 & intergenic & signal transduction \\
\hline rs1111533 & C & 0.05 & 3.53 & Leankg & NPAS3 & intron & Transcription regulation \\
\hline rs41449149 & $\mathrm{T}$ & 0.07 & 3.55 & Leanpct & PRKD1 & intergenic & signal transduction \\
\hline rs10137682 & G & 0.37 & 3.35 & SubQF & NPAS3 & intron & Transcription regulation \\
\hline rs12888531 & C & 0.06 & 3.59 & VF & $S L C 25 A 21$ & intron & solute carrier \\
\hline rs10137682 & G & 0.37 & 3.39 & TAF & NPAS3 & intron & Transcription regulation \\
\hline rs11623278 & G & 0.46 & 4.16 & $\mathrm{RQ}$ & AKAP6 & intergenic & signal transduction \\
\hline rs11161057 & A & 0.42 & 3.42 & REE & MIR548AI & intergenic & mircoRNA \\
\hline rs10137682 & G & 0.37 & 3.50 & REE/weight & NPAS3 & intron & Transcription regulation \\
\hline rs17414154 & A & 0.05 & 3.43 & REE/Lean & AKAP6 & intron & signal transduction \\
\hline rs171112354 & A & 0.08 & 2.95 & FG & $\begin{array}{l}\text { BC148262/MIR4307/ } \\
\text { LOC100505967/NOVA1 }\end{array}$ & intergenic & $\begin{array}{l}\text { CDNA clone/mircoRNA/non coding RNA } \\
\text { paraneoplastic disease antigens }\end{array}$ \\
\hline rs2105274 & G & 0.39 & 3.40 & $\mathrm{Fl}$ & NOVA1 & intergenic & paraneoplastic disease antigens \\
\hline rs1626390 & C & 0.11 & 3.48 & IGR & EGLN3 & intergenic & Transcription regulation \\
\hline rs2105274 & G & 0.39 & 3.47 & HOMA & NOVA1 & intergenic & paraneoplastic disease antigens \\
\hline rs1951758 & $\mathrm{T}$ & 0.36 & 3.21 & $\mathrm{SI}$ & $\begin{array}{l}\text { MIR4307 / LOC100505967 / } \\
\text { NOVA1 }\end{array}$ & intergenic & $\begin{array}{c}\text { mircoRNA/non-coding RNA/paraneoplastic } \\
\text { disease antigens }\end{array}$ \\
\hline rs17114954 & A & 0.04 & 3.32 & SG & MIR548AI & downstream & mircoRNA \\
\hline rs8012040 & G & 0.46 & 3.53 & AIR & $\begin{array}{c}\text { BC148262/LOC100505967/ } \\
\text { NOVA1 }\end{array}$ & intergenic & $\begin{array}{l}\text { CDNA clone / non coding RNA/ } \\
\text { paraneoplastic disease antigens }\end{array}$ \\
\hline rs10483452 & C & 0.27 & 3.82 & $\mathrm{Dl}$ & PPP2R3C & intron & signal transduction \\
\hline rs8006023 & A & 0.05 & 4.60 & TG & NPAS3 & intron & transcription regulation \\
\hline rs8004607 & C & 0.10 & 4.44 & $\mathrm{TC}$ & NPAS3 & intron & transcription regulation \\
\hline rs712300 & C & 0.26 & 4.09 & LDL-C & EGLN3 & intergenic & transcription regulation \\
\hline rs8004607 & C & 0.10 & 3.71 & cal. LDL-c & NPAS3 & intron & transcription factor \\
\hline rs10136818 & $\mathrm{T}$ & 0.02 & 3.63 & HDL-C & STXBP6 & intergenic & exocytosis \\
\hline rs12886242 & G & 0.12 & 2.61 & HMED & NPAS3 & intron & Transcription regulation \\
\hline rs17103757 & G & 0.05 & 3.84 & LMEDn & BRMSIL & intergenic & transcription regulation \\
\hline rs847501 & C & 0.35 & 3.29 & LDLppd & BRMSIL & intergenic & transcription regulation \\
\hline rs10134570 & C & 0.02 & 3.83 & BMED & NPAS3 & intron & Transcription regulation \\
\hline rs1951039 & A & 0.45 & 4.26 & sBP & STXBP6/NOVA1 & intergenic & exocytosis/paraneoplastic disease antigens \\
\hline rs10498306 & C & 0.13 & 4.17 & $\mathrm{dBP}$ & MIR548AI/PRKD1 & intergenic & microRNA/signal transduction \\
\hline rs8007613 & G & 0.28 & 3.04 & Pulse & NPAS3 & intron & Transcription regulation \\
\hline rs9322942 & A & 0.33 & 3.43 & Adiponectin & SRP54 & intron & signal recognition particle $54 \mathrm{kDal}$ \\
\hline rs17427680 & C & 0.05 & 3.12 & Leptin & G2E3 & intergenic & protein sorting \\
\hline
\end{tabular}


Table 3 MetS SNP association with phenotypes and their gene annotation at 14q13 QTL (Continued)

\begin{tabular}{llllclcc}
\hline rs1440983 & A & 0.04 & 3.64 & TNF-alpha & PRKD1 & intergenic & signal transduction \\
rs11849533 & C & 0.17 & 3.67 & IL-1B & NPAS3 & intron & Transcription regulation \\
rs17406989 & T & 0.09 & 2.87 & IL-6 & NPAS3 & intron & Transcription regulation \\
\hline
\end{tabular}

SNPs within 1 LOD reduction from the linkage peak were tested for associations against the 42 phenotypes. Annotated genes and their known function were derived from the NCBI build 36 human genome assembly. Annotations were determined at the position and within $250 \mathrm{~kb}$ up- and downstream of the associated SNP. Data shown in column "-Log10(p)" are levels of the highest association. SNP associations that exceed statistical QTL-specific significance threshold are bolded.

\section{Summary of candidate gene prioritization}

Table 5 summarizes all the biologically relevant cancer or pro-inflammation genes, annotated by the SNP associations and gene expression correlations with MetS phenotypes under the adiponectin QTL peaks of 5p14 and 14q13. Figures 1 and 2 show SNP/ phenotype association plots of SNPs located within these QTLs that we consider to be of the highest priority based on their biological relevance, in relation to the phenotypes from which the top candidate gene was identified.

\section{Discussion}

As previously seen in other studies [36,37] plasma adiponectin was significantly correlated with several of the clinical outcome and biologic precursor phenotypes of MetS in our cohort. It correlated with BMI, total body fat mass, visceral vs. subcutaneous fat distribution, insulin to glucose response indices, levels of plasma lipids/lipoprotein density profiles, and circulating levels of leptin and cytokines (Table 1). As expected, the key clinical traits of MetS are also inter-correlated with each other in our subjects (Additional file 1: Table S1). Using adiponectin level
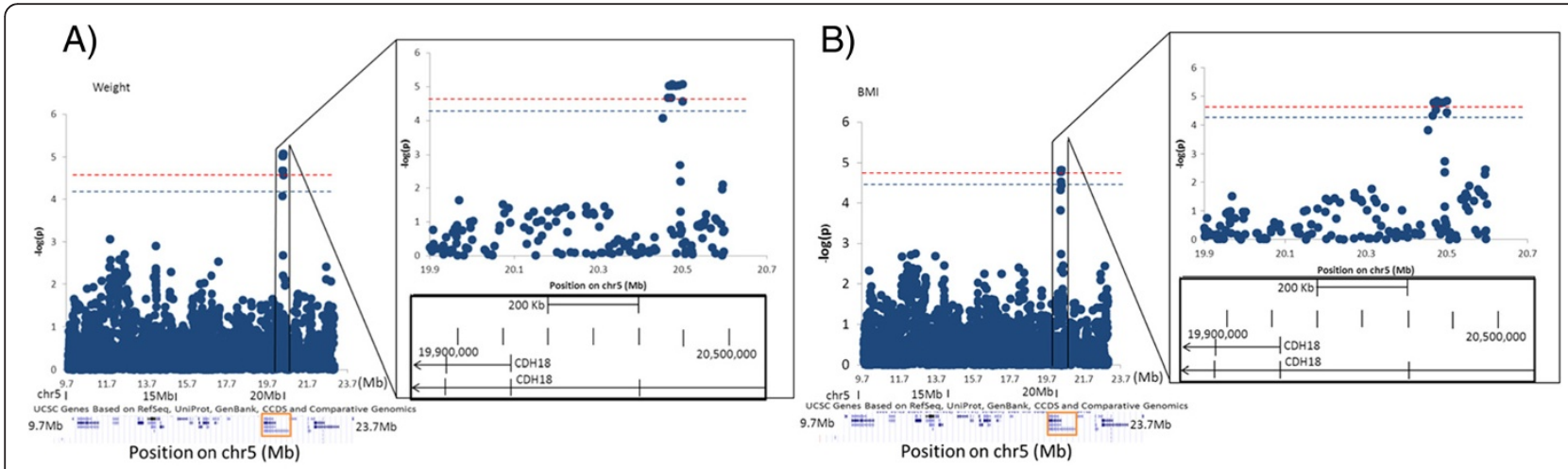

C)

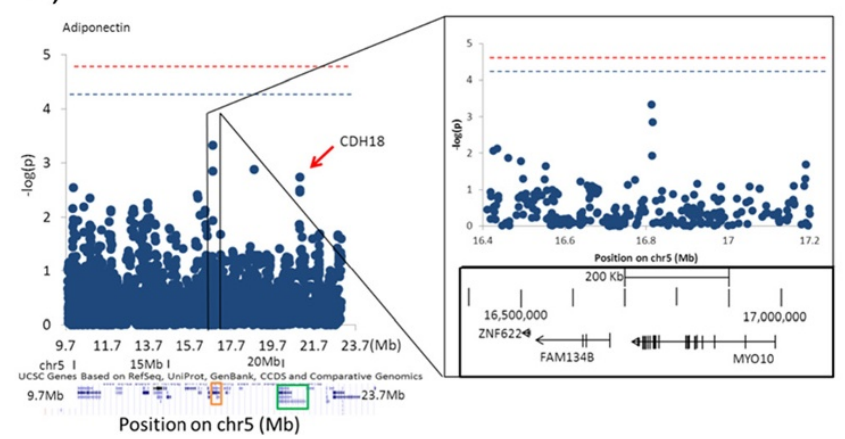

Figure 1 Manhattan plots of SNP associations with MetS phenotypes within adiponectin QTL at 5p14. Dark blue dots depict levels of association of identifier phenotypes with all SNPs in the region determined from 1 LOD reduction from the peak [chr5: 9,792,000-23,021,100 (NCBI36/hg18)]. Vertical axis represents minus logarithm of the p-values and horizontal represents the chromosomal position (Mb). Levels of QTL-wide significance thresholds are shown by the dash lines. Red lines indicate the significant level $\left(p_{a=0.05}=2.11 \times 10^{-5}\right)$ and blue lines indicate suggestive level $\left.p_{a=0.1}=4.11 \times 10^{-5}\right)$. A) Association patterns of all the SNPs of the region with weight phenotype. Transcripts defined by UCSC genome browser $(31,32)$ are shown below the Manhattan plot, by blue bars. SNPS that show highest association with weight are located in gene CDH18 (framed in orange). B) SNP associations with BMI. C) SNP associations with plasma levels of adiponectin. SNPS with strongest associations are mapped to MYO10, shown framed in the lower panel and the blown-up picture. The second locus of peak signals (pointed by an arrow) is mapped to be $400 \mathrm{~kb}$ upstream of $\mathrm{CDH} 18$, framed in green. 

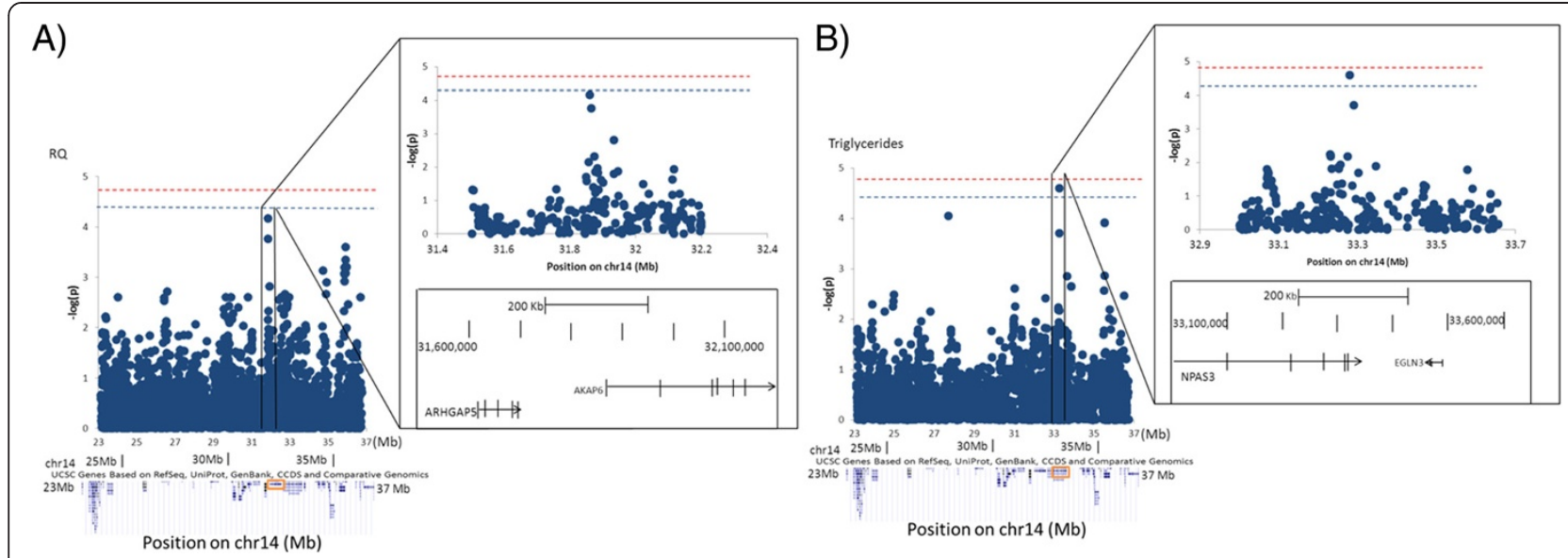

Figure 2 Manhattan plots of SNP associations with MetS phenotypes within adiponectin QTL at 14q13. Dark Blue dots depict levels of association of identifier phenotypes with all SNPs in the region determined from 1 LOD reduction from the peak [chr14: 23,131,000-36,761,868 (NCBI36/hg18)]. Vertical axis represents minus logarithm of the p-values and horizontal represents the chromosomal position (Mb). Levels of QTL-wide significance thresholds are shown by the dash lines. Red lines indicate the significant level $\left(p_{a=0.05}=p_{a=0.05}=1.86 \times 10^{-5}\right)$ and blue lines indicate suggestive level $\left.p_{a=0.1}=3.72 \times 10^{-5}\right)$. A) Association patterns of all the SNPs of the region with RQ phenotype. Transcripts defined by UCSC genome browser (31, 32) are shown below the Manhattan plot, by blue bars. SNPs that show highest association with weight are located in gene AKAP6 (framed in red). B) SNP associations with triglycerides. SNPs that show highest associations with triglycerides are mapped to the transcription factor gene NPAS3.

as a surrogate for MetS, we previously identified two adiponectin-linked QTLs (5p14 and 14q13) in our study population. We now have used SNP association and the cis-effects of local SNPs on PWBC expression to discover MetS-related genes within these two
QTLs. By doing so, we were able to identify multiple novel genes that have significant associations with individual MetS phenotypes. These genes can be mechanistically grouped into four categories (Table 5): (1) cell-cell adhesion and mobility (CDH18, CDH12, CTNND2 and

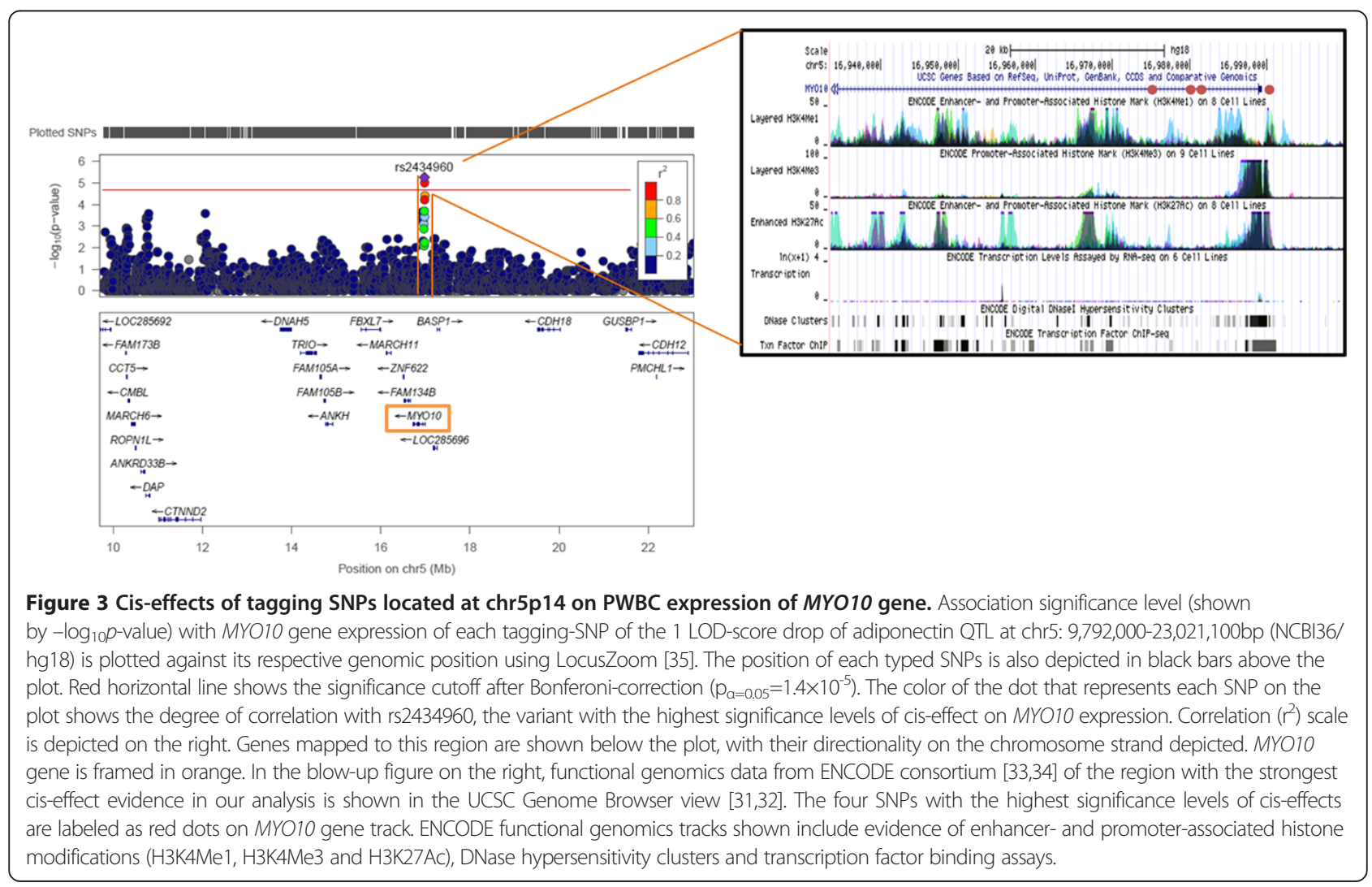


Table 4 Correlation (standardized beta \pm SE) of PWBC expression levels of MYO10 transcript

\begin{tabular}{ccc}
\hline & MetS phenotype & MYO10 $(\boldsymbol{\beta} \pm \mathrm{SE})$ \\
\hline Body Composition & Total Fat Mass (Fatkg), kg & $0.04 \pm 0.11$ \\
& Total Fat Mass (Fatpct), \% & $0.20 \pm 0.11^{*}$ \\
& Total Lean Mass (Leankg), kg & $-0.06 \pm 0.10$ \\
& Total Lean Mass (Leanpct), \% & $-0.20 \pm 0.11^{*}$ \\
\hline Adipokines & Adiponectin, $\mathrm{ng} / \mathrm{mL}$ & $-0.02 \pm 0.09$ \\
& Leptin, $\mathrm{ng} / \mathrm{mL}$ & $0.16 \pm 0.09^{*}$ \\
\hline
\end{tabular}

${ }^{*}$ Correlations with suggestive significance $(p<0.1)$.

MYO10) (2) signal transduction (AKAP, PRKD1 and PPP2R3C); (3) transcription (NPAS3, BRMS1, Nova-1, EGLN3 and TAG); and (4) protein sorting (MARCH11 and $F B X L 7)$. It is interesting that many of these genes are known to play a role in cancer biology. The link between MetS and increased cancer risk is well known [38] thus our prioritized genes provide a possible explanation for the observed association between MetS and cancer.

Our strongest SNPs associations on the chr5 QTL clustered around genes in the cell-cell adhesion pathways (Table 2 and Figure 1). Cell to cell adhesion is a key event in major cellular processes including proliferation, mobility, differentiation and cell death. It is also a basic mechanism facilitating the paracrine communication between cells. CDH18 is a cadherin that is expressed in multiple tissues, most prominently in the CNS [39] and is one of several cadherin genes located in this region of chromosome 5. The $C D H 18$ gene was most strongly associated with weight, BMI, waist circumference and RQ in our cohort, indicating a possible role in the development of body composition. Mechanistically this could be mediated via a role in CNS but since cell adhesion is a phenomenon that is integral to the regional expansion of adipose tissue it is possible that the gene may play a direct role in the preferential deposition of fat into the visceral abdominal region, a fundamental phenotype of MetS. Aberrations leading to alteration of cell adhesion are linked with several tumor types. Ncadherins specifically have been reported to play a role in the formation, growth, invasion [40] and migration of malignant tumors in various settings, including Crohn's disease [41] and prostate cancer [42,43]. Deletions in the region of the chromosome 5 cadherin cluster have been specifically associated with risk of some malignancies [44]. Thus it is possible that the CDH18 gene and other nearby genes identified in cohort (including CTNND2, CDH12 and MYO10) play a mechanistic role in the observed connection between MetS and cancer risk.

Our strongest SNP association signals for plasma adiponectin levels clustered near the gene MYO10 on chr5. MYO10 protein is a member of the myosin family and has a role in trafficking adhesion molecules including integrins and adherins [45]. It is essential for the initiation, stability and formation of filopodia, a "finger-like" cellular protrusion that can sense environmental cues and a key structure for cell motility including cancer cells [46]. In a recent study of breast cancer with poor prognosis, expression of MYO10 is significantly increased in patients with breast cancer. The expression of MYO10 also differentially clustered with clinocopathological markers including p53 mutation, estrogen receptor (ER), tumor grade and patient survival [46]. In our analysis, variants in $M Y O 10$ also associated with lean body mass, LDL diameter and IL-6, thus reflecting pleiotropy in its role in MetS, possibly via modulation of adiponectin levels. No data has shown that MYO10 directly transports CDH18, however our data suggest that these two genes might work together in a biological pathway that predisposes individuals with MetS for carcinogenesis or high risk of metastasis. Our evaluation of the function of these tagging SNPs (or SNPs in LD with these) suggested strong cis-effects of variants near the TSS of MYO10. This region thus may harbor causal SNP(s) that directly affect binding of transcription factors. Results from human cell lines recently published by the ENCODE project has demonstrated that this $17 \mathrm{~kb}$ region is marked with transcription-activating histone modifications, is highly accessible to protein binding, and can be bound by multiple transcription factors in chromatin immunoprecipitation assays (Figure 3) [33,34]. Our approach therefore is able to efficiently identify genetic elements that can function in influencing genes important for our traits of interest.

At the QTL on chr14, SNP associations clustered near genes that function as signal transducers like AKAP6 and transcription factors like NPAS3 (Table 3 and Figure 2). The protein encoded by AKAP6 is an anchor protein for the well-characterized protein kinase A (PKA), also known as AMP-activated protein kinase (AMPK). AKAPs compartmentalize AMPK, thereby regulating AMPK's biological functions. AKAPs by themselves may also function as integrators of AMPK-related signal transduction pathways [47]. AMPK is a key regulator sensing cellular energy status and systemic energy balance [48] and mediates the effects of adipose tissue kinins including adiponectin and leptin in regulating body weight, glucose and lipid homeostasis [48]. It may also play a role in cancer via several processes including arresting of cell cycle progression, triggering inhibition of protein synthesis, and cell growth required in cell proliferation [49]. AMPK is also known to overcome growth factor signaling from a variety of stimuli mediated by the proto-oncogenes Akt and ERK. The AMPK signaling network also contains a number of tumor suppressor genes including p53, which is a universal tumor suppressor [50]. AMPK is thus one of the most prominent biological 
Table 5 Summary of prioritized genes associating MetS with cancer or inflammation

\begin{tabular}{|c|c|c|c|c|c|}
\hline Biological mechanism & $\begin{array}{l}\text { Annotated } \\
\text { genes }\end{array}$ & Biological function & $\begin{array}{l}\text { Association identifier } \\
\text { phenotype }\end{array}$ & Relevance to cancer and/or inflammation & Evidence \\
\hline \multirow[t]{4}{*}{$\begin{array}{l}\text { Cell cell adhesion and } \\
\text { cell motility }\end{array}$} & $\mathrm{CDH} 18$ & $\begin{array}{l}\text { A member of Calcium-dependent cell adhesion } \\
\text { molecules subfamily type } 2 \mathrm{~N} \text {-cadherin, affects } \\
\text { morphogenesis, growth and tissue homeostasis. }\end{array}$ & $\begin{array}{l}\text { weight, BMI, WC, HC } \\
\text { and RQ }\end{array}$ & $\begin{array}{l}\text { Formation, growth, invasion and migration of } \\
\text { malignant tumors, including Crohn's disease and } \\
\text { prostate cancer. Ectopic expression in breast cancer } \\
\text { cells promotes motility, invasion and metastasis. }\end{array}$ & SNP associations \\
\hline & $\mathrm{CDH} 12$ & A member of the cadherin family. & leptin & $\begin{array}{l}\text { Its homologue, } \mathrm{CDH} 11 \text {, promotes synovial fibroblasts } \\
\text { to secret pro-inflammatory cytokines. }\end{array}$ & SNP associations \\
\hline & CTNND2 & $\begin{array}{l}\text { A partner molecule in the cadherin complex. It is } \\
\text { a transcription activator. }\end{array}$ & BMED & Involvement in cancer as above & SNP associations \\
\hline & MYO10 & An associate of the cadherin-catenin complex & $\begin{array}{l}\text { Leankg, LDLppd, } \\
\text { adiponectin, IL-6 }\end{array}$ & $\begin{array}{l}\text { Function unclear, presumably involved in cancer } \\
\text { as above }\end{array}$ & $\begin{array}{l}\text { SNP associations, SNP cis-effects on } \\
\text { gene expression, expression/MetS } \\
\text { phenotype correlations }\end{array}$ \\
\hline \multirow[t]{3}{*}{ Signal transduction } & AKAP6 & $\begin{array}{l}\text { An anchor protein for the AMP-activated protein kinase, } \\
\text { a regulator of glycogen, sugar and lipid metabolism. }\end{array}$ & $\mathrm{HC}, \mathrm{RQ}$ and REE/Lean & $\begin{array}{l}\text { It might be involved in any cancer biology that } \\
\text { is mediated through p53 }\end{array}$ & SNP associations \\
\hline & PRKD1 & $\begin{array}{l}\text { A protein kinase that exerts its function by } \\
\text { phosphorylating target proteins. }\end{array}$ & $\begin{array}{l}\text { WHR, Fatpct, Leanpct, } \\
\text { and TNF-alpha }\end{array}$ & $\begin{array}{c}\text { It is involved in prostate cancer through E-cadherin } \\
\text { phosphorylation }\end{array}$ & SNP associations \\
\hline & PPP2R3C & $\begin{array}{c}\text { It encodes the regulatory component of the protein } \\
\text { ser/thr metallo-phosphatase. May regulate MCM3AP, } \\
\text { which is a phosphorylation-dependent DNA replication } \\
\text { initiation enzyme. Its homologue also play a role in the } \\
\text { activation-induced cell death of B-cells. }\end{array}$ & $\mathrm{DI}$ & $\begin{array}{l}\text { It may presumably be involved in cancer biology that } \\
\text { relates MCM3. These include brain and thyroid cancer. } \\
\text { It may also be involved in inflammation through its } \\
\text { hypothetical function in B cell apoptosis. }\end{array}$ & SNP associations \\
\hline \multirow[t]{7}{*}{ Transcription } & TAG & A novel tumor antigen gene that is immunogenic. & REE,FG, HOMA, HMED & $\begin{array}{l}\text { Testis cancer, skin melanoma and myelogenous } \\
\text { leukemia. }\end{array}$ & SNP associations \\
\hline & NPAS3 & $\begin{array}{l}\text { A transcription factor which regulates neurogenesis, } \\
\text { glucose metabolism and the linkage of the two. }\end{array}$ & $\begin{array}{l}\text { Fatkg, Leankg, SubQF, } \\
\text { TAF, REE/weight, TG, } \\
\text { TC, cal. LDL-c, pulse, } \\
\text { IL-1 } \beta, \text { IL-6 }\end{array}$ & $\begin{array}{c}\text { It is a brain tumor suppressor and a marker for } \\
\text { survival. }\end{array}$ & SNP associations, \\
\hline & & & & & SNP cis-effects on gene expression \\
\hline & NKX2-8 & A homeobox transcription factor & Weight and height & $\begin{array}{l}\text { Fetal liver and hepatocellular carcinoma and } \\
\text { lung cancer }\end{array}$ & SNP associations \\
\hline & BRMS1L & $\begin{array}{l}\text { A homologue to transcription factor BRMS1, which } \\
\text { functions in a histone acetylase complex that repress } \\
\text { target genes }\end{array}$ & LMEDn and LDLppd & Breast cancer progression and melanoma metastasis & SNP associations \\
\hline & NOVA1 & $\begin{array}{c}\text { It is a neuron-specific tumor antigen that has RNA- } \\
\text { binding activity and functions to ensure correct } \\
\text { pre-mRNA splicing of target RNA }\end{array}$ & $\begin{array}{l}\text { BMI, WC, FG, Fl, Sl, AIR, } \\
\text { HMED and sBP }\end{array}$ & It is involved in the paraneoplastic motor disorder & SNP associations \\
\hline & EGLN3 & $\begin{array}{l}\text { It is a hydroxylase for target transcription factor HIF } \\
\text { and mediates apoptosis in neuronal cells under } \\
\text { development }\end{array}$ & IGR and LDL-C & $\begin{array}{l}\text { It is involved in hemangioblastoma, clear cell renal } \\
\text { carcinoma and formation of pheochromocytoma }\end{array}$ & SNP associations \\
\hline \multirow[t]{2}{*}{ Protein sorting } & MARCH11 & $\begin{array}{l}\text { An ubiquitin ligase that is implicated in protein sorting } \\
\text { and transport from trans-Golgi network to } \\
\text { multivascular body. }\end{array}$ & Fatkg, FI, SI and IL-1ß & $\begin{array}{l}\text { Might be involved in pro-inflammatory } \\
\text { cardiomyopathy. }\end{array}$ & SNP associations \\
\hline & FBXL7 & $\begin{array}{l}\text { Another ubiquitin ligase specific for phosphorylated } \\
\text { protein degradation. }\end{array}$ & WHR & Might be involved in pro-inflammation as above & $\begin{array}{l}\text { SNP associations, SNP cis-effects on } \\
\text { gene expression }\end{array}$ \\
\hline
\end{tabular}


molecules proposed to connect metabolic pathways of MetS to cancer [50].

NPAS3, associated with several lipid and cytokine phenotypes in our cohort, encodes a neuronal basic helixloop-helix (Per, Arnt, Sim) domain transcription factor, belonging to a family that has been reported to be crucial for neuronal development and maintenance [51] and exerts a regulatory role in neurogenesis and brain glucose metabolism [52]. Brain tissue of an NPAS3 knockout mouse model shows altered levels of the glycolysis metabolites, the pentose phosphate shunt and Krebs cycle components, and aberrant behavior in mice. Glucose sensing by the brain is known to have effects on feeding, behavior, weight, weight control and associated metabolic consequences, as in MetS. NPAS3 can also modulate cell cycle proliferation, apoptosis, migration and cell invasion and exhibits features of a tumor suppressor. Absence of NPAS3 expression in astrocytomas is a negative prognostic marker for survival [53].

Increasing evidence has suggested that peripheral blood can be used to reveal the relative differences in gene expression among individuals [54,55]. Obtaining gene expression information using peripheral blood is simple and minimally invasive, making it possible to assay a large number of our subjects. Furthermore, obesity can be considered as a low-grade inflammation state [56], due to long-term low-level immune response triggered by accumulation of macrophages in visceral adipose tissue, chronic insulin resistance, adiponkine and cytokine production and malfunctional cardiovascular performance $[57,58]$. Profiling gene expression in peripheral blood therefore may capture changes in the expression of genes important for components of MetS such as visceral adiposity. In our analysis, we found some significant signals of SNP associations near proinflammatory genes. MARCH11 (associated with fat, FI, SI and IL-1beta in our cohort) and FBXL7 (associated with WHR in our cohort) belong to the family of ubiquitin ligases that are engaged in the process of protein sorting and transport of deformed ones from the transGolgi network [59,60]. MARCH11 expression was shown in the Gene Expression Omnibus (GEO) database to be higher in patients with inflammatory dilated cardiomyopathy. $F B X L 7$, an F-box protein family member, is specific for sorting of phosphorylated proteins and their degradation. Thus MARCH11 and FBXL7 may be involved in inflammation, a characteristic phenotype of MetS.

We do acknowledge that PWBC can reveal only a portion of the total gene expression information and that profiling it in other focal tissues like adipose and liver might reveal complementary genomic information. Further exploration of the expression levels of the other genes associated with MetS (and known to play a role in cancer biology) in other target tissues might help to reveal their gene expression correlations with MetS traits.

Our study has identified several novel as well as previously reported genes whose SNP variants are associated with phenotypes that are important components of MetS. e.g. genome-wide study of the genetic basis of insulin resistance reported that a variant of $A K A P 6$ was associated with BMI-adjusted fasting insulin $\left(5 \times 10^{-7}\right)$ in a meta-analysis cohort of European descent [61]. NPAS3 was found in the current study to be associated with a multitude of phenotypes including two inflammatory markers IL-1 $\beta$ and IL-6. Interestingly, in a recent report of a genome-wide search for associations between SNPs and biomarkers of systemic inflammation before and after an anti-inflammatory drug treatment, a variant of NPAS3 was found to be one of the two most significantly associated gene loci with levels of C-reactive protein [62], and studies of visceral adiposity and BMI identified FBXL7, MARCH6 and PRKD1 as candidate loci [63-65].

\section{Conclusions}

In the present study of a family cohort of Northern European origin, we conducted a comprehensive analysis using both SNP associations and gene expression correlations on two previously identified adiponectin QTLs and identified 14 novel genes associated with various metabolic syndrome traits. We found that many of these genes are involved in fundamental cellular functions that could provide a mechanistic link between the development of metabolic syndrome and cancer biology as well as systemic inflammation. Further studies are needed to elucidate the roles these genes play in the development of metabolic syndrome and its relationship with cancer biology. Eventually this could lead to the design of novel diagnostic markers and/or pharmaceutical agents for the prevention and treatment of MetS patients who are at higher risks for developing cancer and systemic inflammation.

\section{Additional file}

Additional file 1: Table S1. Intercorrelation analysis of leading MetS component phenotypes.

\section{Competing interests}

The authors declare that they have no competing interests.

\section{Authors' contributions}

Y.Z. analyzed data, contributed to discussion, wrote and revised the manuscript. J.W.K. performed statistical genetic analyses, contributed to discussion and co-wrote the manuscript. M.O. provided laboratory assistance in genotyping, contributed to discussion and data analysis. O.A. assisted in the phenotyping procedures, contributed to discussion and revision of the manuscript. D.C. assisted in data analysis and contributed to revision of the manuscript. R.M.A. assisted in the phenotyping procedures. U.B. facilitated the genotyping procedures. J.E.C. and M.A.C. did cytokine and transcriptome 
procedures. T.D.D. prepared the genotyping raw data for genetic analysis procedures. A.C. contributed to the original linkage analysis. H.H.H.G. assisted in the transcriptome data analysis. D.L.R. did the lipoprotein particle sizing. J. B. supervised and directed the overall statistical genetic analyses and contributed to discussion. A.H.K designed the study, analyzed data, contributed to discussion and revised the manuscript. All authors read and approved the final manuscript.

\section{Acknowledgements}

Dr. Ahmed Kissebah, the senior author of this work, was fully involved in the preparation of this report up to his death on 17 May 2012. We are saddened by his loss and deeply respectful of his long and distinguished career in obesity research.

We acknowledge the contribution of Roland James (Medical College of Wisconsin), the project manager of TOPS Center for Obesity and Metabolic Research, for his extensive effort in recruitment, phenotyping and database management; Jacqueline Marks (Medical College of Wisconsin) for her supervision of all biochemical procedures; Melena Zelembaba and Regina Cole (Medical College of Wisconsin) for their technical assistance in the Affymetrix chips genotyping procedures; and Ruth Gielow (TOPS Club, Inc.) and her assistants in the recruitment process. Finally, we are most grateful to all the members of TOPS Club, Inc. and their families who volunteered for this study. This work is supported by grants from the NIH (DK071895-03 and DK65598-01) to A.H.K and by TOPS (Take Off Pounds Sensibly) Club, Inc.

\section{Author details}

${ }^{1}$ TOPS Obesity and Metabolic Research Center, Department of Medicine, Medical College of Wisconsin, Milwaukee, Wisconsin, USA. ${ }^{2}$ Human and Molecular Genetics Center, Medical College of Wisconsin, Milwaukee, Wisconsin, USA. ${ }^{3}$ Department of Genetics, Texas Biomedical Research Institute, San Antonio, Texas, USA. ${ }^{4}$ Department of Physiology, Medical College of Wisconsin, Milwaukee, Wisconsin, USA. ${ }^{5}$ Department of Pediatrics, Medical College of Wisconsin, Milwaukee, Wisconsin, USA.

Received: 17 December 2012 Accepted: 23 April 2013 Published: 29 April 2013

\section{References}

1. Day C: Metabolic syndrome, or What you will: definitions and epidemiology. Diab Vasc Dis Res 2007, 4(1):32-38.

2. Russo A, Autelitano M, Bisanti L: Metabolic syndrome and cancer risk. Eur J Cancer 2008, 44(2):293-297.

3. Talvensaari KK, Lanning M, Tapanainen P, Knip M: Long-term survivors of childhood cancer have an increased risk of manifesting the metabolic syndrome. J Clin Endocrinol Metab 1996, 81(8):3051-3055.

4. Chandran M, Phillips SA, Ciaraldi T, Henry RR: Adiponectin: more than just another fat cell hormone. Diab Care 2003, 26:2442-2450.

5. Pajvani UB, Hawkins M, Combs TP, Rajala MW, Doebber T, Berger JP, Wagner JA, Wu M, Knopps A, Xiang AH, Utzschneider KM, Kahn SE, Olefsky JM, Buchanan TA, Scherer PE: Complex distribution, not absolute amount of adiponectin, correlates with thiazolidinedione-mediated improvement in insulin sensitivity. J Biol Chem 2004, 279:12152-12162.

6. Ouchi N, Walsh K: Adiponectin as an anti-inflammatory factor. Clin Chim Acta 2007, 380(1-2):24-30.

7. Kubota N, Terauchi Y, Yamauchi T, Kubota T, Moroi M, Matsui J, Eto K, Yamashita T, Kamon J, Satoh H, Yano W, Froguel P, Nagai R, Kimura S, Kadowaki T, Noda T: Disruption of adiponectin causes insulin resistance and neointimal formation. J Biol Chem 2002, 277(29):25863-25866.

8. Magge SN, Stettler N, Koren D, Levitt Katz LE, Gallagher PR, Mohler ER 3rd, Rader DJ: Adiponectin is associated with favorable lipoprotein profile, independent of $\mathrm{BMI}$ and insulin resistance, in adolescents. J Clin Endocrinol Metab 2011, 96(5):1549-1554.

9. Kelesidis I, Kelesidis T, Mantzoros CS: Adiponectin and cancer: a systematic review. Br J Cancer 2006, 94(9):1221-1225.

10. Comuzzie AG, Funahashi T, Sonnenberg G, Martin LJ, Jacob HJ, Black AE, Maas D, Takahashi M, Kihara S, Tanaka S, Matsuzawa Y, Blangero J, Cohen D, Kissebah A: The genetic basis of plasma variation in adiponectin, a global endophenotype for obesity and the metabolic syndrome. J Clin Endocrinol Metab 2001, 86(9):4321-4325.

11. Kissebah AH, Sonnenberg GE, Myklebust J, Goldstein M, Broman K, James RG, Marks JA, Krakower GR, Jacob HJ, Weber J, Martin L, Blangero J, Comuzzie AG:
Quantitative trait loci on chromosomes 3 and 17 influence phenotypes of the metabolic syndrome. Proc Natl Acad Sci U S A 2000, 97(26):14478-14483.

12. Sonnenberg GE, Krakower GR, Martin $\sqcup$, Olivier M, Kwitek AE, Comuzzie AG, Blangero J, Kissebah AH: Genetic determinants of obesity-related lipid traits. J Lipid Res 2004, 45(4):610-615.

13. Svendsen OL, Haarbo J, Heitmann BL, Gotfredsen A, Christiansen C: Measurement of body fat in elderly subjects by dual-energy $\mathrm{x}$-ray absorptiometry, bioelectrical impedance, and anthropometry. Am J Clin Nutr 1991, 53(5):1117-1123.

14. Peiris AN, Hennes MI, Evans DJ, Wilson CR, Lee MB, Kissebah AH: Relationship of anthropometric measurements of body fat distribution to metabolic profile in premenopausal women. Acta Med Scand Suppl 1988, 723:179-188.

15. Bergman RN: Toward physiological understanding of glucose tolerance. Minimal-model approach. Diabetes 1989, 38:1512-1527.

16. Rainwater DL, Moore PH Jr, Shelledy WR, Dyer TD, Slifer SH: Characterization of a composite gradient gel for the electrophoretic separation of lipoproteins. J Lipid Res 1997, 38(6):1261-1266.

17. Dupont NC, Wang K, Wadhwa PD, Culhane JF, Nelson EL: Validation and comparison of luminex multiplex cytokine analysis kits with ELISA: determinations of a panel of nine cytokines in clinical sample culture supernatants. J Reprod Immunol 2005, 66(2):175-191.

18. Almasy L, Blangero J: Multipoint quantitative-trait linkage analysis in general pedigrees. Am J Hum Genet 1998, 62(5):1198-1211.

19. Burdick JT, Chen W-M, Abecasis GR, Cheung VG: In silico method for inferring missing genotypes in pedigrees. Nat Genet 2006, 38:1002-1004.

20. Göring HH, Curran JE, Johnson MP, Dyer TD, Charlesworth J, Cole SA, Jowett JBM, Abraham L, Rainwater DL, Comuzzie AG, Mahaney MC, Almasy L, MacCluer JW, Kissebah AH, Collier GR, Moses EK, Blangero J: Discovery of expression QTLs using large-scale transcriptional profiling in human lymphocytes. Nat Genet 2007, 39(10):1208-1216.

21. Edgar R, Domrachev M, Lash AE: Gene expression omnibus: NCBI gene expression and hybridization array data repository. Nucleic Acids Res 2002, 30(1):207-210.

22. Boerwinkle $E$, Chakraborty R, Sing CF: The use of measured genotype information in the analysis of quantitative phenotypes in man. I. Models and analytical methods. Ann Hum Genet 1986, 50:181-194.

23. Price AL, Patterson NJ, Plenge RM, Weinblatt ME, Shadick NA, Reich D: Principal components analysis corrects for stratification in genome-wide association studies. Nat Genet 2006, 38:904-909.

24. Moskvina V, Schmidt KM: On multiple testing correction in genome-wide association studies. Genet Epidemiol 2008, 32:567-573.

25. Whitlock MC: Combining probability from independent tests: the weighted Z-method is superior to Fisher's approach. J Evol Biol 2005, 18:1368-1373.

26. Zhang Y, Kent JW Jr, Olivier M, Ali O, Broeckel U, Abdou RM, Dyer TD, Comuzzie AE, Curran JE, Carless MA, Rainwater DL, Goring HHH, Blangero J, Kissebah AH: QTL-based association analyses reveal novel genes influencing pleiotropy of Metabolic Syndrome (MetS). Obesity 2013. accepted.

27. May Executive Summary of The Third Report of The National Cholesterol Education Program (NCEP): Expert panel on detection, evaluation, and treatment of high blood cholesterol in adults (adult treatment panel III). JAMA 2001, 285(19):2486-2497.

28. Alberti KG, Eckel RH, Grundy SM, Zimmet PZ, Cleeman Jl, Donato KA, Fruchart JC, James WP, Loria CM, Smith SC Jr, International Diabetes Federation Task Force on Epidemiology and Prevention; Hational Heart, Lung, and Blood Institute; American Heart Association; World Heart Federation; International Atherosclerosis Society; International Association for the Study of Obesity: Harmonizing the metabolic syndrome: a joint interim statement of the international diabetes federation task force on epidemiology and prevention; national heart, lung, and blood institute; American heart association; world heart federation; international atherosclerosis society; and international association for the study of obesity. Circulation 2009, 120(16):1640-1645.

29. Ho C, Zhou J, Medina M, Goto T, Jacobson M, Bhide PG, Kosik KS: Delta-catenin is a nervous system-specific adherens junction protein which undergoes dynamic relocalization during development. J Comp Neurol 2000, 420(2):261-276.

30. Zhou J, Liyanage U, Medina M, Ho C, Simmons AD, Lovett M, Kosik KS: Presenilin 1 interaction in the brain with a novel member of the Armadillo family. Neuroreport 1997, 8(8):2085-2090. 
31. Kent WJ, Sugnet CW, Furey TS, Roskin KM, Pringle TH, Zahler AM, Haussler D: The human genome browser at UCSC. Genome Res 2002, 12(6):996-1006.

32. UCSC Genome Database. http://genome.ucsc.edu/.

33. ENCODE Project Consortium, Myers RM, Stamatoyannopoulos J, Snyder M, Dunham I, Hardison RC, Bernstein BE, Gingeras TR, Kent WJ, Birney E, et al: A user's guide to the encyclopedia of DNA elements (ENCODE). PLOS Biol 2011, 9(4):e1001046.

34. Rosenbloom KR, Dreszer TR, Long JC, Malladi VS, Sloan CA, Raney BJ, Cline MS, Karolchik D, Barber GP, Clawson H, Diekhans M, Fujita PA, Goldman M, Gravell RC, Harte RA, Hinrichs AS, Kirkup VM, Kuhn RM, Learned K, Maddren M, Meyer LR, Pohl A, Rhead B, Wong MC, Zweig AS, Haussler D, Kent WJ: ENCODE whole-genome data in the UCSC genome browser: update 2012. Nucleic Acids Res 2011, 40(Database issue):1-6.

35. Pruim RJ, Welch RP, Sanna S, Teslovich TM, Chines PS, Gliedt TP, Boehnke M, Abecasis GR, Willer CJ: LocusZoom: Regional visualization of genomewide association scan results. Bioinformatics 2010, 26(18):2336-2337.

36. Koh SB, Yoon J, Kim JY, Yoo BS, Lee SH, Park JK, Choe KH: Relationships between serum adiponectin with metabolic syndrome and components of metabolic syndrome in non-diabetic Koreans: ARIRANG study. Yonsei Med J 2011, 52(2):234-241.

37. Patel DA, Srinivasan SR, Xu JH, Chen W, Berenson GS: Adiponectin and its correlates of cardiovascular risk in young adults: the Bogalusa heart study. Metabolism 2006, 55(11):1551-1557.

38. Esposito K, Chiodini P, Colao A, Lenzi A, Giugliano D: Metabolic syndrome and risk of cancer: a systematic review and meta-analysis. Diabetes Care 2012, 35(11):2402-2411.

39. Gene Expression Atlas at the European Bioinformatics Institute. http://www.ebi. ac.uk/gxa/gene/ENSG00000145526? ef=cell_type.

40. Hazan RB, Phillips GR, Qiao RF, Norton L, Aaronson SA: Exogenous expression of $\mathrm{N}$-cadherin in breast cancer cells induces cell migration, invasion, and metastasis. J Cell Biol 2000, 148(4):779-790

41. Burke JP, Cunningham MF, Sweeney C, Docherty NG, O'Connell PR: N-cadherin is overexpressed in Crohn's stricture fibroblasts and promotes intestinal fibroblast migration. Inflamm Bowel Dis 2011, 17(8):1665-1673.

42. Gravdal K, Halvorsen OJ, Haukaas SA, Akslen LA: A switch from E-cadherin to $\mathrm{N}$-cadherin expression indicates epithelial to mesenchymal transition and is of strong and independent importance for the progress of prostate cancer. Clin Cancer Res 2007, 13(23):7003-7011.

43. Tanaka H, Kono E, Tran CP, Miyazaki H, Yamashiro J, Shimomura T, Fazli L, Wada R, Huang J, Vessella RL, An J, Horvath S, Gleave M, Rettig MB, Wainberg ZA, Reiter RE: Monoclonal antibody targeting of N-cadherin inhibits prostate cancer growth, metastasis and castration resistance. Nat Med 2010, 16(12):1414-1420.

44. Kajikawa Y, Ikeda M, Takemoto S, Tomoda J, Ohmaru N, Kusachi S: Association of circulating levels of leptin and adiponectin with metabolic syndrome and coronary heart disease in patients with various coronary risk factors. Int Heart J 2011, 52(1):17-22.

45. Almagro S, Durmort C, Chervin-Pétinot A, Heyraud S, Dubois M, Lambert O, Maillefaud C, Hewat E, Schaal JP, Huber P, Gulino-Debrac D: The motor protein myosin-X transports VE-cadherin along filopodia to allow the formation of early endothelial cell-cell contacts. Mol Cell Biol 2010, 30(7):1703-1717.

46. Arjonen A, Kaukonen R, Ivaska J: Filopodia and adhesion in cancer cell motility. Cell Adh Migr 2011, 5(5):421-430.

47. Michel JJ, Scott JD: AKAP mediated signal transduction. Annu Rev Pharmacol Toxicol 2002, 42:235-257

48. Kahn BB, Alquier T, Carling D, Hardie DG: AMP-activated protein kinase: ancient energy gauge provides clues to modern understanding of metabolism. Cell Metab 2005, 1(1):15-25.

49. Carretero J, Medina PP, Blanco R, Smit L, Tang M, Roncador G, Maestre L, Conde E, Lopez-Rios F, Clevers HC, Sanchez-Cespedes M: Dysfunctional AMPK activity, signalling through mTOR and survival in response to energetic stress in LKB1-deficient lung cancer. Oncogene 2007, 26(11):1616-1625.

50. Motoshima H, Goldstein BJ, Igata M, Araki E: AMPK and cell proliferationAMPK as a therapeutic target for atherosclerosis and cancer. J Physiol 2006, 574:63-71.

51. Rutter J, Reick M, Wu LC, MCKnight SL: Regulation of clock and NPAS2 DNA binding by the redox state of NAD cofactors. Science 2001, 293(5529):510-514.
52. Sha L, Macintyre L, Machell JA, Kelly MP, Porteous DJ, Brandon NJ, Muir WJ, Blackwood DH, Watson DG, Clapcote SJ, Pickard BS: Transcriptional regulation of neurodevelopmental and metabolic pathways by NPAS3. Mol Psychiatry 2012, 17:267-279.

53. Moreira F, Kiehl TR, So K, Ajeawung NF, Honculada C, Gould P, Pieper RO, Kamnasaran D: NPAS3 demonstrates features of a tumor suppressive role in driving the progression of Astrocytomas. Am J Pathol 2011, 179(1):462-476

54. Charlesworth JC, Curran JE, Johnson MP, Göring HHH, Dyer TD, Diego VP, Kent JW, Mahaney MC, Almasy L, MacCluer JW, Moses EK, Blangero J: Transcriptomic epidemiology of smoking: the effect of smoking on gene expression in lymphocytes. BMC Medical Genomics 2010, 3:29.

55. Yamaoka M, Maeda N, Nakamura S, Kashine S, Nakagawa Y, Hiuge-Shimizu A, Okita K, Imagawa A, Matsuzawa Y, Matsubara K, Funahashi T, Shimomura I: A pilot investigation of visceral fat adiposity and gene expression profile in peripheral blood cells. PLoS One 2012, 7(10):e47377.

56. Scarpellini E, Tack J: Obesity and metabolic syndrome: an inflammatory condition. Dig Dis 2012, 30(2):148-153.

57. Hotamisligil GS: Endoplasmic reticulum stress and the inflammatory basis of metabolic disease. Cell 2010, 140:900-917.

58. Neels JG, Olefsky JM: Inflamed fat: what starts the fire? J Clin Invest 2006, 116:33-35.

59. Morokuma Y, Nakamura N, Kato A, Notoya M, Yamamoto Y, Sakai Y, Fukuda H, Yamashina S, Hirata Y, Hirose S: MARCH-XI, a novel transmembrane ubiquitin ligase implicated in ubiquitin-dependent protein sorting in developing spermatids. J Biol Chem 2007, 282(34):24806-24815.

60. Cenciarelli C, Chiaur DS, Guardavaccaro D, Parks W, Vidal M, Pagano M: Identification of a family of human F-box proteins. Curr Biol 1999, 9(20):1177-1179.

61. Manning AK, Hivert MF, Scott RA, Grimsby JL, Bouatia-Naji N, Chen H, Rybin D, Liu CT, Bielak LF, Prokopenko I, Amin N, Barnes D, Cadby G, Hottenga JJ, Ingelsson E, Jackson AU, Johnson T, Kanoni S, Ladenvall C, Lagou V, Lahti J, Lecoeur C, Liu Y, Martinez-Larrad MT, Montasser ME, Navarro P, Perry JR, Rasmussen-Torvik $\sqcup$, Salo P, Sattar N, et al: A genome-wide approach accounting for body mass index identifies genetic variants influencing fasting glycemic traits and insulin resistance. Nat Genet 2012, 44(6):659-669.

62. Aslibekyan S, Kabagambe EK, Irvin MR, Straka RJ, Borecki IB, Tiwari HK, Tsai MY, Hopkins PN, Shen J, Lai CQ, Ordovas JM, Arnett DK: A genome-wide association study of inflammatory biomarker changes in response to fenofibrate treatment in the genetics of lipid lowering drug and diet network. Pharmacogenet Genomics 2012, 22(3):191-197.

63. Fox CS, Liu Y, White CC, Feitosa M, Smith AV, Heard-Costa N, Lohman K, GIANT Consortium; MAGIC Consortium; GLGC Consortium, Johnson AD, Foster MC, Greenawalt DM, Griffin P, Ding J, Newman AB, Tylavsky F, Miljkovic I, Kritchevsky SB, Launer L, Garcia M, Eiriksdottir G, Carr JJ, Gudnason V, Harris TB, Cupples LA, Borecki IB: Genome-wide association for abdominal subcutaneous and visceral adipose reveals a novel locus for visceral fat in women. PLoS Genet 2012, 8(5):e1002695.

64. Wang KS, Liu X, Zheng S, Zeng M, Pan Y, Callahan K: A novel locus for body mass index on 5 p15.2: a meta-analysis of two genome-wide association studies. Gene 2012, 500(1):80-84.

65. Speliotes EK, Willer CJ, Berndt SI, Monda KL, Thorleifsson G, Jackson AU, Lango Allen H, Lindgren CM, Luan J, Mägi R, Randall JC, Vedantam S, Winkler TW, Qi L, Workalemahu T, Heid IM, Steinthorsdottir V, Stringham HM, Weedon MN, Wheeler E, Wood AR, Ferreira T, Weyant RJ, Segrè AV, Estrada K Liang L, Nemesh J, Park JH, Gustafsson S, Kilpeläinen TO, et al: Association analyses of 249,796 individuals reveal 18 new loci associated with body mass index. Nat Genet 2010, 42(11):937-948.

doi:10.1186/1755-8794-6-14

Cite this article as: Zhang et al: A comprehensive analysis of adiponectin QTLs using SNP association, SNP cis-effects on peripheral blood gene expression and gene expression correlation identified novel metabolic syndrome (MetS) genes with potential role in carcinogenesis and systemic inflammation. BMC Medical Genomics 2013 6:14. 